\title{
Catchment land use predicts benthic vegetation in small estuaries
}

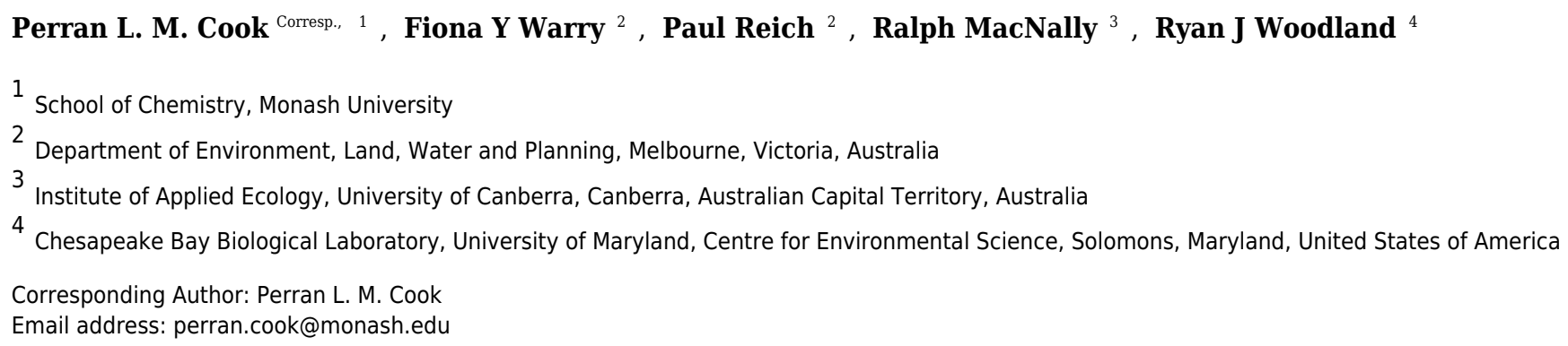

Many estuaries are becoming increasingly eutrophic from human activities within their catchments. Nutrient loads often are used to assess risk of eutrophication to estuaries, but such data are expensive and time consuming to obtain. We compared the percent of fertilized land within a catchment, dissolved inorganic nitrogen loads, catchment to estuary area ratio and flushing time as predictors of the proportion of macroalgae to total vegetation within 14 estuaries in south-eastern Australia. The percent of fertilized land within the catchment was the best predictor of the proportion of macroalgae within the estuaries studied. There was a transition to a dominance of macroalgae once the proportion of fertilized land in the catchment exceeded $24 \%$, highlighting the sensitivity of estuaries to catchment land use. 


\section{Catchment land use predicts benthic vegetation in small estuaries}

2

3 Perran L. M. Cook*1, Fiona Y. Warry ${ }^{1}$, Paul Reich ${ }^{2}$, Ralph MacNally ${ }^{3}$, Ryan J. Woodland ${ }^{4}$

4

$5 \quad{ }^{1}$ Water Studies Centre, Monash University, Clayton, Australia

6

$7 \quad{ }^{2}$ Department of Environment, Land, Water and Planning, Arthur Rylah Institute for

8 Environmental Research, Riparian and Estuarine Ecology Program, Heidelberg, Victoria,

9 Australia

10

$11{ }^{3}$ Institute for Applied Ecology, The University of Canberra, Bruce, Australian Capital Territory, 12 Australia

13

$14{ }^{4}$ Chesapeake Biological Laboratory, University of Maryland Center for Environmental Science, 15 Solomons, Maryland, United States of America

16

17

18

19

20 


\section{Abstract}

22

23 Many estuaries are becoming increasingly eutrophic from human activities within their

24 catchments. Nutrient loads often are used to assess risk of eutrophication to estuaries, but such

25 data are expensive and time consuming to obtain. We compared the percent of fertilized land

26 within a catchment, dissolved inorganic nitrogen loads, catchment to estuary area ratio and

27 flushing time as predictors of the proportion of macroalgae to total vegetation within 14 estuaries

28 in south-eastern Australia. The percent of fertilized land within the catchment was the best

29 predictor of the proportion of macroalgae within the estuaries studied. There was a dominance of

30 macroalgae once the proportion of fertilized land in the catchment exceeded $24 \%$, highlighting

31 the sensitivity of estuaries to catchment land use. 


\section{Introduction}

34 Estuaries are well recognized for their ecological and economic value, by supporting diverse

35 natural communities, highly productive fisheries, and recreational amenity (McLusky \& Elliott

36 2004). Being at the terminus of drainage basins, estuaries are impacted by increased nutrient

37 loads delivered to the coastal zone. Intensive monitoring of both catchments and estuaries has

38 clearly and consistently implicated nutrient loads, in particular nitrogen, as the drivers of

39 multiple adverse ecological responses, including initiation of algal blooms, hypoxia and

40 alteration of secondary production (Hauxwell \& Valiela 2004, Conley et al. 2009).

41 Unfortunately, detailed time-series of nutrient-loading data are not readily available for most

42 estuaries around the world, and a widely applicable and pragmatic approach is required to assess

43 ecological risk and guide land use planning and management targets more generally.

44 Given that much of the change in nutrient loads is related to human land-use intensity, an

45 alternative approach is to assess ecological risk in estuaries from land-use data, which typically

46 are more readily available than nutrient data (Brinson et al. 2013). The effectiveness of land use

47 data at acting as a proxy for risk to estuaries will depend on the level of detail of classification.

48 Ideally land use should be classified into types of agriculture which have a wide range of nutrient

49 emissions. In practice however, this level of detail is rarely available, and more broad

50 classifications such as forest, urban areas and agriculture are more typically available. In addition

51 to land use, it is important to consider other interacting variables such as estuary flushing time

52 and catchment to estuary area ratio. Estuaries with a fast flushing rate are likely to be less

53 impacted by activities in their catchment than ones with a low flushing rate. Similarly, large

54 estuaries receiving inputs from a small catchment are less likely to be impacted than small

55 estuaries receiving inputs from a larger catchment area. 
To link land use to estuary ecological status requires an ecological indicator that is

57

responsive to eutrophication and the identification of a plausible link between that indicator and measureable land-use characteristics. This indicator needs to be both sensitive to changes in nutrient loads and preferably easy to measure. Chlorophyll a (as a proxy for phytoplankton biomass) is a widely used measure of eutrophication that is relatively easy to obtain and strongly related to catchment land use (Meeuwig 1999). Despite this, phytoplankton dynamics are much influenced by local conditions within estuaries and the often pulsed nature of inputs, resulting in great spatial and temporal variability of chlorophyll a measurements (e.g., Cook et al. (2010)). Therefore, spatially and temporally intensive sampling in an estuary is required for representative and reliable quantification of chlorophyll a. Remote sensing may allow the integration of chlorophyll a concentrations both temporally and spatially, but the complex optical properties of coastal waters has hindered this approach, leading to limited success in relating remotely sensed estimates of chlorophyll a to land use (Le et al. 2015).

An alternative to chlorophyll a that is more stable over short times scales is the ratio of macroalgae area to seagrass area (or macroalgae to total vegetation, MA:TV ratio), which has been shown to increase globally with increased nutrient loading as fast growing macroalgae overgrow seagrass (Hauxwell \& Valiela 2004, Woodland et al. 2015). The generality of the MA:TV ratio, which can be effectively monitored using ground-truthed aerial photographs, suggests that this ratio could provide a suitable proxy for relating remotely sensed land-use characteristics to estuarine eutrophication in shallow estuaries that is easier to obtain and more spatially representative than chlorophyll a.

The aim of this study was to investigate whether land use data available within a national Australian database (Stein et al. 2014) could be used to predict the ecological condition of 
79 estuaries. Such information can provide land management agencies with a cost effective and

80 rapid approach to assessing ecological risk to estuaries to enable better prioritization of resources

81 for monitoring and restoration. To do this, we combined previously published data on nutrient

82 loading and estuarine responses with land-use characteristics to compare the efficacy of nutrient

83 load estimates, catchment to estuary area ratio, estuary flushing time and land use as predictors

84 of eutrophication as indicated by the ratio of macroalgae to total vegetation (MA:TV ratio) and 85 chlorophyll a within southern Australian estuaries.

86

\section{Materials and Methods}

88 The macroalgae to total vegetation (MA:TV) ratio and chlorophyll a data for 14 estuaries in the 89 southeastern Australian state of Victoria are from Woodland et al. (2015). Methods describing

90 field collections, data processing and calculations are described in detail there, so we only briefly

91 outline them here. The estuaries were selected to represent a gradient across land use and nutrient

92 loading, and be geographically representative of the Victorian coastline. Estuary selection also

93 included considerations of total area and geomorphology to avoid scaling-effects arising from

94 large-scale differences in hydrological conditions among estuaries. The MA:TV data represent

95 snapshots in time based on areal photographs taken between January and February 2012 that

96 were validated by underwater video footage. Video data were reviewed in the laboratory and

97 bottom cover at each drop site was assigned to one or more of the following four primary habitat

98 types: seagrass, macroalgae, bare sediment/unvegetated rocky reef, or channel habitat ( $>2 \mathrm{~m}$

99 depth). Seagrass and macroalgae habitats were further classified as having sparse-medium $(<$

$10050 \%)$ or dense (50-100\%) vegetation coverage. In the case of seagrass habitats with conspicuous

101 epiphytic or intermingled macroalgae, the site was assigned to both habitat categories and each 
102 category was assigned a density classification. Spatial mapping was carried out in ArcGIS by

103 constructing habitat raster maps (cell size $=2 \mathrm{~m}^{2}$ ) based on visual reconciliation of site specific

104 habitat classifications and photographic information from composite aerial images. Vegetated

105 habitat areas were weighted by coverage classifications such that map cells assigned sparse or

106 medium coverage were considered to contain 50\% vegetation and dense coverage $=100 \%$

107 vegetation. For example, a $10 \mathrm{~m}^{2}$ patch of medium seagrass was designated as having $5 \mathrm{~m}^{2}$ of

108 seagrass habitat and $5 \mathrm{~m}^{2}$ of bare sediment. Total areas of each estuary and each coverage

109 weighted habitat class were calculated and exported for further analysis. Seagrass species were

110 primarily composed of Zostera spp. (includes Z. muelleri and Z. nigracaulis) or Ruppia spp.

111 Macroalgal communities included several genera (e.g., Ulva, Enteromorpha, Hypnea,

112 Gracilaria) associated with eutrophication (McGlathery 2001).

113 Surface (c. $0.2-0.5 \mathrm{~m}$ depth) chlorophyll concentrations $\left(\mu \mathrm{g} \mathrm{L}^{-1}\right)$ were monitored on two

114 successive outgoing tidal cycles on three separate occasions in a subset of $n=8$ estuaries.

115 Sampling occurred once for each estuary during the spring (September-October), early summer

116 (November-December) and late summer (January-February) of 2011-2012. Chlorophyll

117 measurements were taken adjacent to the main channel of the estuary with a calibrated Hydrolab

118 water quality sonde (model DSX5). Concentration values were averaged for each occasion $(n=3-$

11916 observations) and across each of the three seasons to yield an integrated mean chlorophyll

120 concentration in the surface waters of each estuary.

121 For each estuary and upstream river catchment, potential predictors of variation in the

122 MA:TV ratios were obtained from the National Environmental Stream Attributes database (Stein

123 et al. (2014); v1.1.5, Geoscience Australia website: www.ga.gov.au). These predictors included

124 four summaries of upstream river catchment land use: proportion modified by human 
125 development, proportion with population density $\geq 1$ person $\mathrm{km}^{-2}$, proportion urbanized, and

126 proportion receiving or generating fertilizers (predominantly residential areas, grazing pasture,

127 horticulture). We included several covariates that might affect the relationships between the

128 responses and predictors: (1) estuary flushing time (days); (2) the measured areal loading rate of

129 dissolved inorganic nitrogen (DIN) to each estuary (tonnes DIN km² of estuary $\mathrm{yr}^{-1}$ ) (Woodland

130 et al. (2015); and (3) the catchment area to estuary area ratio (C:E). Nitrogen loads were

131 measured based on stream flow and nutrient concentrations measured close to the head of the

132 estuary ( salinity $=0$ ), and encompassed $>90 \%$ of the catchment. River flow $\left(\mathrm{ML} \mathrm{d}^{-1}\right)$ from

133 gauging stations and nutrient and concentration data $\left(\mathrm{mg} \mathrm{L}^{-1}\right)$ for each river system over the 13-

134 yr interval from 2000 to 2012 were obtained by downloading archived data from the Department

135 of Environment, Land, Water and Planning Water Measurement Information System website

136 (data.water.vic.gov.au/monitoring.htm) or provided by Melbourne Water

137 (melbournewater.com.au). We focused our analysis on total nitrogen (TN), oxidized dissolved

138 forms of nitrogen $\left(\mathrm{NO}_{3}{ }^{-}\right.$and $\mathrm{NO}_{2}{ }^{-}$, hereafter simply DIN). River flow was measured daily;

139 whereas, nutrient sampling intervals ranged from approximately biweekly $(\mathrm{n}=23)$ to quarterly $(\mathrm{n}=$

$1403-4$ ) with an average of $n=12$ samples per river system per year (i.e., monthly sampling). Data

141 were assigned to a 01 June-31 May hydrologic year rather than a calendar year to reflect the

142 annual flow-nutrient cycle responsible for primary production dynamics in Victorian estuaries

143 during the austral summer(Cook \& Holland 2012). Annual loads ( $\left.\mathrm{Mg} \mathrm{yr}^{-1}\right)$ of TN, DIN, TP and

144 TSS were estimated from measured river flow and concentration data using a flow-stratified

145 Kendall Ratio (Kendall et al. 1983) approach within a Monte-Carlo simulation-based spreadsheet

146 routine (Tan et al. 2005). This method has previously been shown to give the same results as

147 those independently published by the Victorian EPA (Cook \& Holland 2012). 
149 deposition in this region is negligible $(<10 \%)$ compared to total loads in these small estuaries.

150 The C:E ratio was included to account for small estuaries fed by a large catchment which would

151 inflate areal nutrient loads and estuary flushing time was included to account for the well-known

152 effect of residence time in modulating eutrophication. To place the gradient of catchment land

153 use intensity within the broader context of the literature, we calculated nutrient export rates from

154 upper and lower quartiles of fertilized catchments (corresponding to $>85 \%$ and $<10 \%$

155 fertilization, respectively) by dividing the total load from the catchment by the total land area of 156 the catchments.

157 Statistical analysis

158 We first screened predictors for high collinearity. If there were sets of predictors with pair-wise 159 correlations $>0.7$, we eliminated all predictors bar one. The retained predictor was the one with 160 the lowest sum of correlations with predictors other than those in the inter-correlated set. Land

161 use and riverine DIN concentrations were highly correlated ( $r=0.84)$, so DIN concentration was

162 excluded from the analysis because it is dependent upon land use. We scrutinized the

163 distributions of the retained predictors. Several were extremely right-skewed, so these were log-

164 transformed (designated by $\dagger$ in Table 1). Once the distributions were near normally or near

165 uniformly distributed, we standardized (mean $=0$, standard deviation $=1)$ the predictors to make 166 the ranges of all predictors comparable and to assist in model convergence.

167 We used two approaches to identify the potentially important predictors and to identify

168 the relative importance of these predictor variables. First, we used Bayesian variable selection

169 using stochastic search (O'Hara \& Sillanpää 2009). This method identifies those predictors that

170 had high posterior probabilities of being included in the best models for explaining variation in 
171 the MA:TV ratio. We used the posterior odds ratio framework to assess predictor importance

172 (Kass \& Raftery 1995). A predictor is assigned an uninformative prior for being included in the

173 best model (a predictor is equally likely to be selected as not), which corresponds to a prior odds

174 ratio of 0.5 (included):0.5 (not included) $=1$. If the posterior probability of inclusion, after

175 calculations, is (or exceeds) 0.75 , then the posterior odds are 0.75 (included):0.25 (not included)

$176=3$. The ratio of the posterior odds to the prior odds is the posterior odds ratio (here $0.75: 0.25 /$

$1770.5: 0.5=3$ ), with values exceeding 3 being indicative of probable importance of a predictor in

178 explaining variation in the response variable (here MA:TV ratio). Models were calculated using

179 JAGS (Plummer 2003).

180

Second, we used hierarchical partitioning (HP) on the predictor variables to calculate the

181

182

183

184

185

186

187

188

189

190

191 192 fertilization $(F)$. The model was:

193 each predictor (Mac Nally 1996).

relative proportions independently explained by each predictor. We used the hier.part (Walsh \& Mac Nally 2004) package in R (R Development Core Team 2011). HP complements Bayesian model selection by quantifying the relative amounts of variation independently explained by

The \%fertilized predictor proved to be important (Table 1) but we were concerned that its effect might be moderated by the catchment to estuary $(\mathrm{C}: \mathrm{E})$ ratio or residence time of the estuary (Tf). Therefore, we used Bayesian model selection and HP analyses for a full interaction model involving these three predictors, notwithstanding that the $\mathrm{C}$ : $\mathrm{E}$ ratio and $\mathrm{Tf}$ were not important from the analyses in Table 1. The full interaction model included the three predictors, each pair of interactions, and the three-way interaction (see Table 2).

We fitted a change-point model for the relationship between MA:TV and \%catchment

$$
M A: T V_{i} \sim N o r m a l\left(\mu_{i}, \sigma\right),
$$

$$
\mu_{i}=\alpha * \delta\left(F_{i}-\gamma\right)+\beta_{1} * \delta\left(\gamma-F_{i}\right) * F_{i}+\beta_{2} * \delta\left(F_{i}-\gamma\right) * F_{i}
$$


194 where: $\delta$ is unity if the argument is non-negative and zero otherwise and $\gamma$ is the change-point.

195 The priors were: $\alpha, \beta_{i} \sim \operatorname{Normal}(0, \sigma=2)$, and $\gamma \sim \operatorname{Uniform}(0,100)$. The program JAGS

196 (Plummer 2003), which uses a Gibbs sampler, was used to fit the relationship; there were 12,000

197 iterations and 5000 ‘burns-in’ samples. We checked convergence using Gelman-Rubin methods 198 (convergence of multiple independent chains).

\section{Results}

The proportion of fertilization within a catchment was the only important predictor of the

204 MA:TV ratio within our set of estuaries (Table 1). There was little evidence that interactions

205 between the proportion of fertilization and residence time or the ratio of the catchment area to estuary area were important (Table 2). Macroalgal dominance in estuaries was positively associated with an increasing proportion of the catchment receiving fertilizers (Fig. 1), with macroalgal cover dominating benthic vegetation in estuaries with catchments that had $>20 \%$ of the catchment with fertilization. The change point model was a good fit to the data, with $R^{2}=$ 0.93 (Fig. 1). The change-point $\gamma$ was estimated to be $24.3 \pm 9.9 \mathrm{SD}$ (\% catchment fertilization). The intercept, $\alpha$, was 0.675 for points above the change-point and 0 otherwise. The slopes were: $\beta_{1}=0.024$ (slope for points below the change-point) and $\beta_{2}=0.002$ (points above the change-

213 point). There was little evidence for a relationship between chlorophyll a and \% catchment 214 fertilization (linear regression, $R^{2}=0.14, P>0.05$ ), although all estuaries with catchments $>$ $21520 \%$ fertilized land had average chlorophyll $a$ concentrations $>6 \mu \mathrm{g} / \mathrm{L}$ during the late spring to 216 late summer growth period. Similarly, there was little evidence for a relationship between the 217 proportion of the estuary area covered by benthic vegetation and proportion of the catchment 218 receiving fertilizers $\left(R^{2}=0.17, P>0.05\right)$. Total nitrogen $(\mathrm{N})$ and dissolved inorganic nitrogen 
219 (DIN) exports were $0.22-1.7$ and $0.063-0.74 \mathrm{~kg} \mathrm{ha}^{-1} \mathrm{yr}^{-1}$ respectively for the catchments in the 220 lower quartile of fertilization ( $<10 \%$ area fertilized) and $1.9-6$ and $0.7-3.1 \mathrm{~kg} \mathrm{ha}^{-1} \mathrm{yr}^{-1}$ for the 221 catchments in the upper quartile of fertilization ( $>80 \%$ area fertilized). 


\section{Discussion}

224 Land use as a predictor of shallow benthic vegetation

225 The results show that land use is a strong predictor of the proportion of macroalgae to total

226 vegetation within south-eastern Australian estuaries. Although the current analysis shows that

227 land use is a stronger predictor than nitrogen loads, we do not interpret this to mean that nitrogen

228 inputs to estuaries are not the key driver of changes to estuarine benthic vegetation. Rather we

229 use these findings to shed light on the possible mechanisms through which nutrients drive change

230 within estuaries and how catchment land use integrates this change.

231 The proportion of the catchment receiving fertilization was a better predictor of the

232 MA:TV ratio than was areal dissolved inorganic nitrogen (DIN) load, which we have previously

233 suggested to be a better predictor of MA:TV in these estuaries than total nitrogen (TN) or total

234 phosphorous (TP) loads (Woodland et al. 2015). This outcome arose because there was a

235 relatively weak relationship between measured loads (both total and normalized to the estuary

236 area) and the total area fertilized $\left(\mathrm{km}^{2}\right)$ within catchments $\left(R^{2}=0.33\right)$. The lack of such a

237 relationship is consistent with previous studies that have shown nitrogen attenuation factors can

238 be highly variable (Elwan et al. 2015). Therefore, the relationship between land use and

239 estuarine response is not just driven by a land-use-load relationship, as we had expected.

240 There was a strong non-linear relationship between DIN concentration in the rivers and

241 the MA:TV ratio $\left(R^{2}=0.78\right.$, when DIN concentration is log transformed $)$ arising from the

242 relationship between land use and DIN concentrations within the rivers (Woodland et al. 2015).

243 However, we do not believe that the nutrient concentrations observed within the rivers are the

244 primary driver of changes in the MA:TV ratio because these rivers drain into estuaries of greatly

245 different sizes and hence dilution. Moreover, there was no relationship between DIN and the 
246 MA:TV ratio when the nutrient concentration was normalized to estuary area. These results

247 suggest that catchment land-use metrics 'integrate' factors affecting the amount and availability

248 of nutrients within the estuary that control the MA:TV ratio, which are missed by instantaneous

249 measurements of load. Catchment land-use metrics may incorporate: (1) the historical sequence

250 of delivery of nitrogen $(\mathrm{N})$ and total suspended solids that are trapped and recycled or re-

251 suspended within the estuary; (2) increased bioavailability of particulate and dissolved organic $\mathrm{N}$

252 delivered to estuaries as fertilization increases (Seitzinger et al. 2002, Petrone et al. 2009); and

253 (3) local groundwater inputs of $\mathrm{N}$ directly to tidal areas (Wong et al. 2014).

254 Our results suggest that estuarine vegetation structure can be substantially altered when

255 agricultural land use constitutes as little as $24 \%$ of the catchment. Therefore, it is instructive to

256 compare the nutrient loading and export rates measured here with previous studies to place the

257 land-use intensity in this study in a wider context. The areal loading rates of $\mathrm{N}$ in these estuaries

258 span the range reported globally for estuaries, ranging $10^{2}-10^{5} \mathrm{mmol} \mathrm{N} \mathrm{m}^{-2} \mathrm{yr}^{-1}$ as total $\mathrm{N}$

259 (Woodland et al. 2015). The rates of $\mathrm{N}$ generation from the catchments in the lowest quartile of

$260 \%$ fertilization averaged 0.9 and $0.25 \mathrm{~kg} \mathrm{ha}^{-1} \mathrm{yr}^{-1}$ for TN and DIN respectively (Table 3), which

261 are at the lower end of DIN exports of 0 to $10 \mathrm{~kg} \mathrm{ha}^{-1} \mathrm{yr}^{-1}$ reported in forested catchments

262 (Bernal et al. 2005, Brookshire et al. 2012). Our undisturbed catchments have lower exports than

263 forested catchments elsewhere in the world, highlighting the relatively oligotrophic state of

264 estuaries fed by pristine catchments in Australia. For the most fertilized catchments ( $>80 \%$

265 fertilization), we saw average $\mathrm{N}$ generation rates of $\sim 4.5$ and $1.9 \mathrm{~kg} \mathrm{ha}^{-1} \mathrm{yr}^{-1}$ for TN and DIN

266 respectively, which are comparable with reported nutrient generation rates for mixed

267 farming/rural land use in southeastern Australia (Drewry et al. 2006). Our N generation rates are

268 at the lower end of reported nutrient generation rates of 4-14 $\mathrm{kg} \mathrm{ha}^{-1} \mathrm{yr}^{-1}$ for TN in European and 
269 North American systems (Howarth et al. 1996), highlighting that even small amounts of

270 relatively low-intensity agriculture can lead to large changes in benthic vegetation in these

271 naturally oligotrophic estuaries. Studies from other locations are needed to investigate whether

272 the patterns observed here are globally applicable.

273

274 The use of the macroalgae to total vegetation ratio as an indicator of estuarine condition

275 It is virtually impossible to select an ecological indicator that represents all critical aspects of 276 ecosystem function. Our choice of MA:TV was based on the requirement that we could easily 277 obtain relevant data for large areas of the estuary. In shallow estuaries, such as those studied 278 here, macroalgae is widely considered an indicator of eutrophication (Valiela et al. 1997). There 279 are cascading ecological consequences from the increasing dominance of macroalgal biomass to 280 food webs, from changes in consumer biodiversity, productivity and trophic relationships (e.g., 281 omnivory) to biogeochemical cycling and dissolved-oxygen dynamics (Sogard \& Able 1991, 282 Valiela et al. 1997). Consistent with this, we also saw that once catchment fertilization exceeded $28320 \%$, and alongside a transition to macroalgal dominance of demersal vegetation, all chlorophyll 284 a measurements were $>6 \mu \mathrm{g} / \mathrm{L}$, which typically is regarded as eutrophic (Hakanson et al. 2007). The ability to reliably predict MA:TV ratio using just one variable differs from previous 286 studies that have shown that multiple predictors are needed to explain $>50 \%$ of the variation of 287 other response variables ( $\mathrm{Li}$ et al. 2007, Greene et al. 2015). One of the strongest relationships 288 from previous reports has been between chlorophyll a and the area of agriculture land use in a catchment and estuary volume $\left(R^{2}\right.$ of 0.68$)$ in 14 Canadian estuaries (Meeuwig 1999). This is not unexpected because a certain nutrient load will be diluted to different extents depending on 291 estuary volume. Similarly, one would expect phytoplankton concentration to be sensitive to 
292 estuarine residence time, which will lead to different wash-out rates (Nixon et al. 2001). We saw

293 no clear relationship between chlorophyll a and percent fertilization in our data set, which was

294 consistent with the need for other variables to describe the response of this parameter.

295 We found no important relationship between seagrass or total vegetation areal extent and

296 land use. Elsewhere, a combination of land-use and physical factors, such as tidal range and

297 mean wave height, were needed to describe seagrass areal extent (Li et al. 2007), illustrating the

298 interplay of factors other than eutrophication in controlling seagrass distribution. By

299 standardizing macroalgal extent as a proportion of total vegetation, our analysis reduces the

300 influence of physical factors, such as sediment movement and hydrodynamics, that often limit

301 the growth of benthic vegetation. The MA:TV measure also accounts for estuaries with different

302 hypsometric profiles because the MA:TV ratio is functionally constrained to those areas where

303 light penetration can support benthic vegetation. Change point analysis showed that the MA:TV

304 ratio increased at a lower rate above a catchment fertilization of $24 \%$. This probably suggests

305 that any increase in biomass above this point may have manifested itself as increased thickness

306 (as opposed to area). Alternatively, macroalgae became growth limited at high biomass due to

307 limitation by other factors such as light and/or space. Therefore, a disadvantage of this approach

308 is that it does not sensitively distinguish between moderate and high levels of disturbance.

309 The interaction model showed that estuary flushing time did not contribute much to

310 explaining variation in the MA:TV response. The residence times used in our study are relatively

311 short (0.6-4.2 days compared to months to years for lagoons), which may partially explain the

312 lack of importance of residence time. However, macroalgae can assimilate $\mathrm{N}$ in several hours

313 and, given the subsequent relatively slow turnover of $\mathrm{N}$, residence time may not significantly

314 affect the macroalgal response (Nixon et al. 2001). Lagoon systems, with much longer residence 
315 times, are likely to respond differently to our estuaries because phytoplankton are more dominant

316 in systems where water residence time exceeds phytoplankton turnover time (Hauxwell \&

317 Valiela 2004). As the catchment-estuary area ratio (C:E ratio) increased, we expected that

318 nutrient inputs would be distributed over a smaller estuarine area and may render estuaries more

319 sensitive to the proportion of fertilizing land uses in the catchment. The results of the interaction

320 model, which included C:E ratio (Table 2), suggested that there was little evidence of an

321 interaction of the C:E ratio with the proportion of fertilizing land uses in the catchment. As the

322 C:E ratio increased, the transit time of loads delivered to the estuary decreased, leading to lower

323 retention and exposure to nutrients within the system compared to estuaries with lower C:E

324 ratios. Systems with low C:E ratios have the load spread over a larger area, but with a longer

325 transit time, leading to higher retention and exposure to nutrients. Our results suggest that these

326 opposing effects may largely cancel each other out, leading to the C:E ratio having no

327 perceptible effect on MA:TV.

328

329

Application to management

330 Although nutrient loads are a critical management tool for receiving waters, the expense and

331 long time frame required to collect and meaningfully interpret these data mean that such data are

332 not always available. However, land-use information typically is much more readily available,

333 and as has been illustrated here and previously (Meeuwig 1999, Meeuwig et al. 2000), can

334 provide a good indicator of likely risk to estuaries. Once estuaries at risk have been identified,

335 there should be a further assessment of ecological impact. The MA:TV ratio provides a relatively

336 rapid and spatially representative indication of ecological response and condition. By way of an

337 example case study, an Index of Estuary Condition (IEC) is being used to assist the prioritization 
338 of estuary management investment thereby supporting the Victorian Waterway Management

339 Program, Australia (DEPI 2013). Indicators that have demonstrated relationships with processes

340 threatening estuaries (e.g. nutrient loading and land-use change) are essential if broad scale

341 resource condition assessments are to be interpretable, ecologically meaningful and useful for

342 management (Barbour et al. 2000, Stoddard et al. 2008). For these reasons the MA:TV index is

343 being incorporated into the Victorian IEC.

344

\section{Conclusion}

346 The proportion of catchment fertilization is a strong predictor of the proportion of macroalgae

347 relative to seagrass in small south-eastern Australian estuaries. Our results suggest that estuaries

348 are sensitive to land-use change, and that conversion of as little as $20 \%$ of a catchment to

349 fertilized land uses can substantially shift the dominance of benthic primary produces from

350 seagrass to macroalgae. The use of simple land-use measures may provide a strong indicator of

351 risk of estuarine eutrophication where other data are absent. Further studies across a wider

352 geographic and climatic spread are required to investigate relationships between catchment land 353 use and estuarine vegetation globally.

\section{Acknowledgements}

356 We thank Walter Boynton and Francis Burdon for helpful suggestions on the manuscript. 


\section{References}

358 Barbour MT, Swietlik WF, Jackson SK, Courtenmanch DL, Davies SP, Yoder CO (2000)

359

360

361

362

363

364

365

366

367

368

369

370

371

372

373

374

375

376

377

378

379

380

381

382

383

384

385

386

387

388

389

390

391

392

393

394

395

396

397

398

399

400

401

402 Measuring the attainment of biological integrity in the USA: a critical element of ecological integrity. . Hydrobiologia 422:453-464

Bernal S, Butturini A, Sabater F (2005) Seasonal variations of dissolved nitrogen and DOC : DON ratios in an intermittent Mediterranean stream. Biogeochemistry 75:351-372

Brinson M, Rheinhardt R, Ferrell R, Duncan B, Hobbs L, McNaught D, Phelan J, Rader D (2013) A rapid watershed assessment approach for assessing the condition of small, coastal watersheds: Protocol and case study. Ocean \& Coastal Management 71:238255

Brookshire ENJ, Gerber S, Menge DNL, Hedin LO (2012) Large losses of inorganic nitrogen from tropical rainforests suggest a lack of nitrogen limitation. Ecology Letters 15:916

Conley DJ, Paerl HW, Howarth RW, Boesch DF, Seitzinger SP, Havens KE, Lancelot C, Likens GE (2009) ECOLOGY Controlling Eutrophication: Nitrogen and Phosphorus. Science 323:1014-1015

Cook PLM, Holland DP (2012) Long term nutrient loads and phytoplankton dynamics in a large temperate Australian lagoon system affected by recurring blooms of Nodularia spumigena. Biogeochemistry 107:261-274

Cook PLM, Holland DP, Longmore AR (2010) Effect of a flood event on the dynamics of phytoplankton and biogeochemistry in a large temperate Australian lagoon. Limnology \& Oceanography 55:1123-1133

DEPI (2013) Victorian Waterway Management Strategy. Department of Environment and Primary Industries, Melboure

Drewry JJ, Newham LTH, Greene RSB, Jakeman AJ, Croke BFW (2006) A review of nitrogen and phosphorus export to waterways: context for catchment modelling. Mar Freshw Res 57:757-774

Elwan A, Singh R, Horne D, Roygard J, Clothier B Nitrogen attenuation factor: Can it tell a story about the journey of nutrients in different subsurface environments? In: Currie LD, Burkitt LL (eds). Proc Moving farm systems to improved attenuation. Fertiliser and Lime Research Centre, Massey University

Greene CM, Blackhart K, Nohner J, Candelmo A, Nelson DM (2015) A National Assessment of Stressors to Estuarine Fish Habitats in the Contiguous USA. Estuaries and Coasts 38:782-799

Hakanson L, Bryhn AC, Hytteborn JK (2007) On the issue of limiting nutrient and predictions of cyanobacteria in aquatic systems. Sci Total Environ 379:89-108

Hauxwell J, Valiela I (2004) Effects of nutrient loading on shallow seagrass-dominated coastal systems: patterns and processes. In: Nielsen SL, Banta GT, Pedersen MF (eds) Estuarine nutrient cycling: the influence of primary producers. Kluwer Academic Publishers, Dordrecht

Howarth RW, Billen G, Swaney D, Townsend A, Jaworski N, Lajtha K, Downing JA, Elmgren R, Caraco N, Jordan T, Berendse F, Freney J, Kudeyarov V, Murdoch P, Zhu ZL (1996) Regional nitrogen budgets and riverine N\&P fluxes for the drainages to the North Atlantic Ocean: Natural and human influences. Biogeochemistry 35:75-139

Kass RE, Raftery AE (1995) Bayes factors. Journal of the American Statistical Association 90:773-795. 
403 Kendall A, Stuart A, Ord JK (1983) Advanced theory of statistics, , Vol 3. Griffin, London

404 Le CF, Lehrter JC, Hu CM, Schaeffer B, MacIntyre H, Hagy JD, Beddick DL (2015) Relation

405

406

407

408

409

410

412

413

414

415

416

417

418

419

420

421

422

423

424

425

426

427

428

429

430

431

432

433

434

435

436

437

438

439

440

441

442

443

444

445

446

447

448 between inherent optical properties and land use and land cover across Gulf Coast estuaries. Limnol Oceanogr 60:920-933

Li XY, Weller DE, Gallegos CL, Jordant TE, Kim HC (2007) Effects of watershed and estuarine characteristics on the abundance of submerged aquatic vegetation in Chesapeake Bay subestuaries. Estuaries and Coasts 30:840-854

Mac Nally R (1996) Hierarchical partitioning as an interpretative tool in multivariate inference. Austral Ecology 21:224-228

McGlathery K (2001) Macroalgal blooms contribute to the decline of seagrass in nutrientenriched coastal waters. J Phycol 37:453-456

McLusky DS, Elliott M (2004) The Estuarine Ecosystem: Ecology, Threats and Management. Oxford University Press, Oxford

Meeuwig JJ (1999) Predicting coastal eutrophication from land-use: an empirical approach to small non-stratified estuaries. Marine Ecology Progress Series 176:231-241

Meeuwig JJ, Kauppila P, Pitkänen H (2000) Predicting coastal eutrophication in the Baltic: a limnological approach. Can J Fish Aquat Sci 57:844-855

Nixon S, Buckley B, Granger S, Bintz J (2001) Responses of very shallow marine ecosystems to nutrient enrichment. Human and Ecological Risk Assessment 7:1457-1481

O'Hara RB, Sillanpää MJ (2009) A review of Bayesian variable selection methods: what, how and which. Bayesian Analysis 4:85-117

Petrone KC, Richards JS, Grierson PF (2009) Bioavailability and composition of dissolved organic carbon and nitrogen in a near coastal catchment of south-western Australia. Biogeochemistry 92:27-40

Plummer M JAGS: A program for analysis of Bayesian graphical models using Gibbs sampling. Proc Proceedings of the 3rd International Workshop on Distributed Statistical Computing

R Development Core Team (2011) R: A language and environment for statistical computing. R Foundation for Statistical Computing, Vienna, Austria. ISBN 3-900051-07-0, URL http://www.r-project.org/.

Seitzinger SP, Sanders RW, Styles R (2002) Bioavailability of DON from natural and anthropogenic sources to estuarine plankton. Limnol Oceanogr 47:353-366

Sogard SM, Able KW (1991) A comparison of eelgrass, sea lettuce macroalgae, and marsh creeks as habitats for epibenthic fishes and decapods. Estuar Coast Shelf Sci 33:501519

Stein JL, Hutchinson MF, Stein JA (2014) A new stream and nested catchment framework for Australia. Hydrol Earth Syst Sci 18:1917-1933

Stoddard JL, Herlihy AT, Peck DV, Hughes RM, Whittier TR, Tarquinio E (2008) A process for creating multimetric indices for large-scale aquatic surveys. Journal of the North American Benthological Society 27: 878-891

Tan KS, Fox D, Etchells T (2005) Generator for uncertainty measures and load estimates using alternative formulae. Australian Centre for Envirometrics, The University of Melbourne, Melbourne

Valiela I, McClelland J, Hauxwell J, Behr PJ, Hersh D, Foreman K (1997) Macroalgal blooms in shallow estuaries: Controls and ecophysiological and ecosystem consequences. Limnol Oceanogr 42:1105-1118 
449 Walsh CJ, Mac Nally R (2004) "The hier.part Package"

450 Wong WW, Cartwright IC, Grace MR, Cook PLM (2014) Sources and fate of nitrate in a

451

452 groundwater-fed estuary elucidated using stable isotope ratios of nitrogen and oxygen. Limnology \& Oceanography 59:1493-1509

453 Woodland RJ, Thomson JR, Mac Nally R, Reich P, Evrard V, Walker JP, Cook PLM (2015)

$454 \quad$ Nitrogen loads explain primary productivity in estuaries at the ecosystem scale.

455

Limnology \& Oceanography 60:1751-1762

456 


\section{Figure 1}

Plot of MA:TV vs \% of catchment fertilised

The ratio of macroalgae to total vegetation (MA:TV) versus the $\%$ of the catchment receiving fertilizer inputs. Scatterplots show observed (open circles) and fitted (solid circles) for the change-point analysis, with the estimated position of the change-point shown by a dashed vertical line.

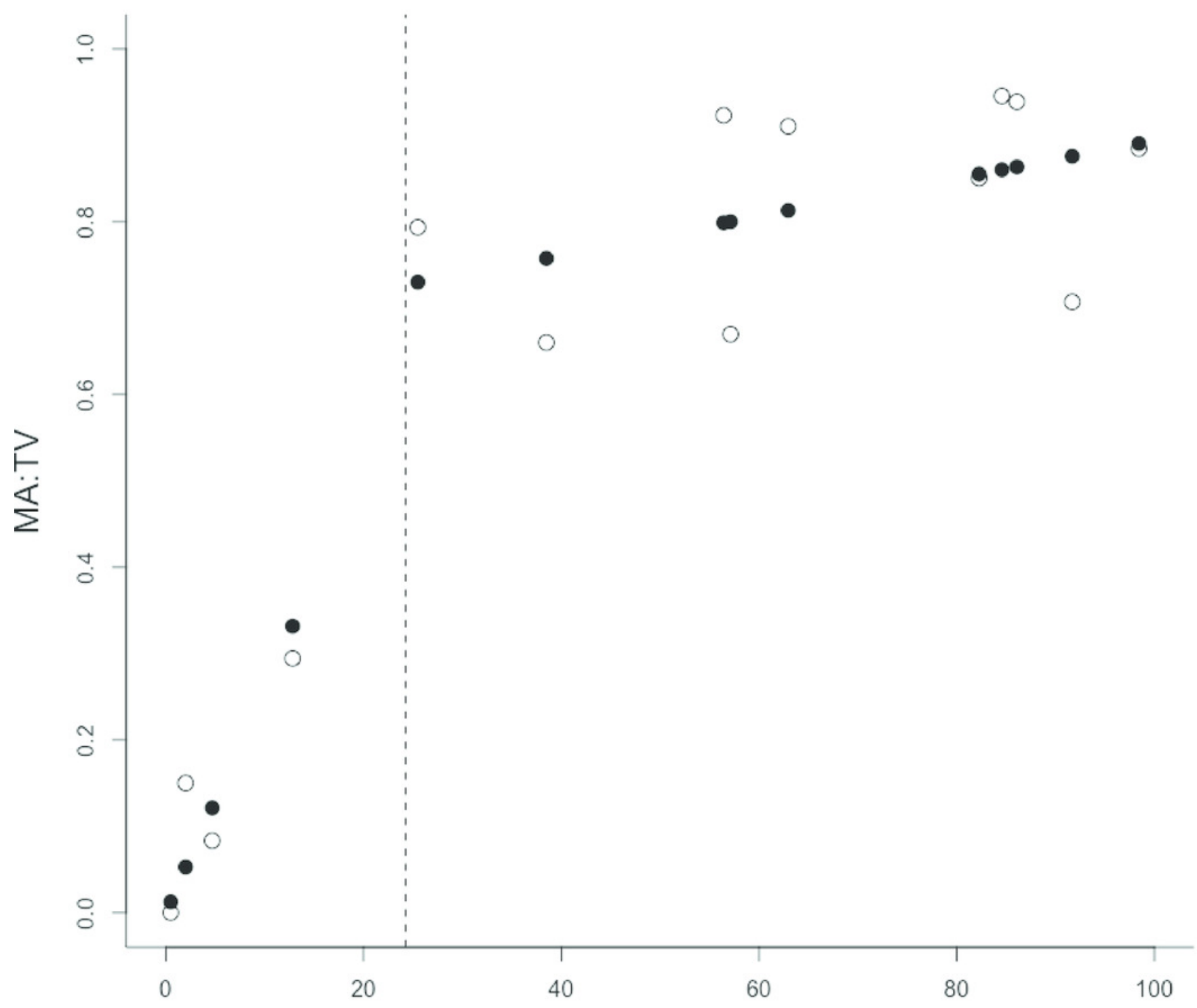




\section{Table $\mathbf{1}$ (on next page)}

Results of Bayesian variable selection and hierarchical partitioning

Results of Bayesian variable selection and hierarchical partitioning, which show the predictor variables for the macroalgae to total vegetation (MA:TV) ratio, the posterior probability of inclusion predictor $\operatorname{Pr}(\operatorname{Inc})$, the regression coefficient $(\beta)$, the standard deviation of beta $\operatorname{SD}(\beta)$ and the $\%$ of the variability independently explained by each variable. Predictors are abbreviated as follows: C:E ratio is the catchment area to estuary area ratio, Tf is the estuary flushing time, Pop_Prop_ 1 is the proportion of the catchment with a human population $>1$ $\mathrm{km}^{-2}, \%$ Modified is the proportion of the catchment modified by human development, \% urbanized is the proportion of the catchment urbanized, \% Fertilized the proportion of catchment likely to receive fertilizer inputs, and the Areal.DIN.load is the load of inorganic nitrogen to each estuary normalized to surface area. 


\begin{tabular}{lcccc}
\hline Predictor Variable & $\operatorname{Pr}(\operatorname{Inc})^{*}$ & $\beta$ & $\mathrm{SD}(\beta)$ & \%indep. \\
\hline$\dagger \mathrm{C}:$ E ratio & 0.04 & 0.01 & 0.03 & 6 \\
Tf & 0.02 & $<0.01$ & 0.03 & 6 \\
Pop_Prop_1 & 0.02 & $<0.01$ & 0.02 & 8 \\
$\%$ Modified & 0.02 & $<0.01$ & 0.02 & 5 \\
$\dagger \%$ Urbanized & 0.03 & $<0.01$ & 0.02 & 13 \\
$\dagger \%$ Fertilized & 1.0 & 0.30 & 0.04 & 46 \\
$\dagger$ Areal.DIN.load & 0.03 & $<0.01$ & 0.02 & 15 \\
\hline
\end{tabular}

- Values $>0.75$ are deemed to be statistically important

- $\quad$ †Ln-transformed 


\section{Table 2 (on next page)}

Results of Bayesian variable selection for potential interaction terms

Results of Bayesian variable selection for potential interaction terms showing the posterior probability of inclusion predictor $\operatorname{Pr}(\operatorname{Inc})$, the regression coefficient $(\beta)$, the standard deviation of beta $\mathrm{SD}(\beta)$ and the \% of the variability independently explained by each variable (as for Table 1) computed using hierarchical partitioning. 


\begin{tabular}{lcccc}
\hline Interaction terms & $\operatorname{Pr}(\mathrm{Inc})$ & $\beta$ & $\mathrm{SD}(\beta)$ & $\%$ indep. \\
\hline$\dagger \mathrm{C}:$ E ratio & 0.067 & 0.016 & 0.026 & 12 \\
$\mathrm{Tf}$ & 0.025 & -0.004 & 0.019 & 6 \\
$\dagger \%$ Fertilized & 1.0 & 0.294 & 0.042 & 52 \\
$\dagger \mathrm{C}:$ E ratio $\times \mathrm{Tf}$ & 0.016 & 0.002 & 0.016 & 3 \\
$\dagger \mathrm{C}:$ E ratio $\times \dagger$ & & & & \\
$\quad$ \% Fertilized & 0.068 & -0.013 & 0.034 & 14 \\
$\mathrm{Tf} \times \dagger \%$ Fertilized & 0.023 & 0.006 & 0.018 & 4 \\
$\mathrm{Tf} \times \dagger \mathrm{C}:$ E ratio $\times \dagger$ & & & & \\
$\quad \%$ Fertilized & 0.030 & & & \\
\hline
\end{tabular}

- Values $>0.75$ are deemed statistically important

- $\quad$ iLn-transformed 


\section{Table 3(on next page)}

Nutrient export rates for total nitrogen (TN) and NOx for the catchments in this study

Comparisons for exports from forest and mixed farming are given for SE Australia. \% Fertilized exports from catchments are all given in $\mathrm{kg} \mathrm{ha}^{-1} \mathrm{y}^{-1}$. Published export rates for Australian forest and mixed farming/rural land uses are from Drewry et al. (2006) . 


\begin{tabular}{lccc}
\hline System & \%_Fertilized & NOx & TN \\
\hline Wingan River & 0.49 & 0.06 & 1.7 \\
Cann River & 2.0 & 0.08 & 0.22 \\
Genoa River & 4.7 & 0.11 & 0.62 \\
Aire River & 13 & 0.74 & 1.0 \\
Gellibrand River & 25 & 1.3 & 3.1 \\
Merriman Creek & 35 & 0.38 & 1.1 \\
Tarra River & 38 & 1.6 & 2.5 \\
Werribee River & 56 & 0.11 & 0.35 \\
Patterson River & 57 & 0.33 & 1.2 \\
Glenelg River & 63 & 0.24 & 0.65 \\
Kororoit Creek & 82 & 0.28 & 0.56 \\
Tarwin River & 85 & 3.1 & 6.1 \\
Curdies River & 86 & 0.70 & 2.4 \\
Bass River & 92 & 3.1 & 7.7 \\
Moyne River & 98 & 0.79 & 1.9 \\
\hline Forest & - & - & $0.9-2$ \\
Mixed farming/rural & - & 4 & $0.5-4.5$ \\
\hline
\end{tabular}

